\title{
Proposta metodológica para avaliar graus de implementação da Política Nacional de Recursos Hídricos em distintas escalas de planejamento
}

\section{Methodological approach to assess degrees of implementation of the National Water Resources Policy at different planning scales}

Data de entrada:

$13 / 11 / 2018$

Data de aprovação: 20/12/2018

Yáscara Maia Araújo de Brito ${ }^{1 *}$ | Márcia Maria Rios Ribeiro' | Simone Rosa da Silva² |

Yvonilde Dantas Pinto Medeiros ${ }^{3}$ | Wanessa Dunga de Assis ${ }^{1}$

DOI: https://doi.org/10.36659/dae.2020.042

\section{ORCID ID}

Brito YMA (D) https://orcid.org/0000-0002-8933-6058

Ribeiro MMR (D) https://orcid.org/0000-0002-3446-6752
Silva SR (D) https://orcid.org/0000-0001-7138-7546

Medeiros YDP (D) https://orcid.org/0000-0003-0456-5976

Assis WD (D) https://orcid.org/0000-0003-3744-0635

\section{Resumo}

Este artigo define critérios objetivando avaliar graus de implementação da Política Nacional de Recursos Hídricos (PNRH) em duas escalas de planejamento: uma bacia de rio de domínio da União (nível macro) e uma sub-bacia de rio de domínio estadual (nível micro). Sete critérios são propostos: cinco instrumentos de gestão (Lei no 9433/97) - outorga; cobrança; sistemas de informações, planos de recursos hídricos e enquadramento e duas condições de participação pública e gestão de conflitos - existência e atuação dos comitês de bacia e incidência de conflitos pelo uso da água. Cinco categorias de graus de implementação foram definidas: Muito Alto, Alto, Médio, Baixo e Muito Baixo. A metodologia foi aplicada à Bacia Hidrográfica do rio São Francisco e à sua sub-bacia do rio Salitre (BA). A análise mostra diferentes graus de implementação da PNRH em função da escala de planejamento (União ou Estado) e do critério analisado, apontando a necessidade de ações de gestão para apoiar a tomada de decisão em distintas escalas de planejamento.

Palavras-chave: Planos de bacia. Dupla dominialidade. Conflitos pelo uso da água. Brasil.

\section{Abstract}

This article defines criteria to evaluate the degree of implementation of the National Water Resources Planning (PNRH) in two planning scales: a river basin under the Union domain (macro level) and a river sub-basin under state domain (micro level). Seven criteria are proposed: five management tools (considering the Law 9433/97) _water permits; water charge; water resources information systems, water resource plans and water quality objectives and two conditions for public participation and conflict management $\neg$ existence and performance of basin committees and incidence of conflicts over water use. Five categories of implementation degrees were defined: Very High, High, Medium, Low, and Very Low. The methodology was applied for the São Francisco River Basin and to Salitre sub-basin (BA). The analysis shows different degrees of PNRH implementation depending on the planning scale (Union or State) and the criterion analyzed, pointing out the need for management actions to support decision making at different planning scales.

Keywords: Water resource plans. Water double domain. Water resources conflicts. Brazil.

\footnotetext{
${ }^{1}$ Universidade Federal de Campina Grande (UFCG) - Campina Grande - Paraíba - Brasil.

${ }^{2}$ Escola Politécnica da Universidade de Pernambuco (UPE) - Recife - Pernambuco - Brasil.

${ }^{3}$ Escola Politécnica da Universidade Federal da Bahia (UFBA) - Salvador - Bahia - Brasil.

* Autora correspondente: yascaramaiaaagmail.com.
} 


\section{INTRODUÇÃO}

Diferentes escalas são consideradas nos estudos da hidrologia e da governança hídrica em função das dimensões a serem ressaltadas. Daniell e Barretau (2014) apresentam sete categorias de escalas que podem ser de interesse dos estudos hídricos: i) espacial (baseada na topografia, como no caso de bacias hidrográficas ou outras áreas administrativas); ii) temporal (tempo é uma importante dimensão nos estudos hidrológicos e que trará consequências para o entendimento do fenômeno estudado, por exemplo, se cheias ou secas); iii) administrativa ou jurisdicional (essa escala se relaciona com a camada na qual será feita a administração do recurso, podendo ser em nível local, regional, nacional, internacional; é uma das escalas mais usadas na governança de água); iv) institucional (essa escala está muito vinculada às escalas espacial e administrativa, sendo concernente às regras que podem variar desde uma constituição até leis, políticas, regras operacionais); v) gerenciamento (vinculada às atividades do planejamento e com interações com as escalas espacial, administrativa e institucional; vi) de redes (essa escala não é explicitamente considerada na literatura da governança de água, mas pode ser vista sob dois ângulos: a) o social - indivíduos, famílias, comunidades que interagem entre si e, b) o hídrico, na sua dimensão física - redes de abastecimento de água são o melhor exemplo); vii) conhecimento e informação (relaciona-se com o tipo de informação e conhecimento que podem ser específicos ou gerais relevantes para uso nas escalas espacial, institucional, administrativa).

A escala de gerenciamento discutida em Daniell e Barretau (2014) é objeto desta pesquisa, na qual é chamada de escala de planejamento. Como afirmado pelos autores, as atividades do planejamento podem se dar em três níveis: nível mais baixo (o das tarefas); o nível intermediário (das leis e políticas) e o nível mais alto (das es- tratégias). $O$ aspecto da escala do planejamento hídrico e integração entre os setores envolvidos é uma discussão relevante para a governança de água. Assim, para garantir uma boa governança de água, a coordenação entre diferentes escalas de planejamento e entre distintas autoridades é essencial. Há desafios nesse processo. A descentralização da gestão hídrica, por exemplo, é um deles. Se a descentralização cria a oportunidade de considerar a política de água na escala local (como discutido em AKHMOUCH et al., 2017), ela também faz crescer os desafios de coordenação.

Deve-se atentar, nessa discussão, para os conceitos de governança de água e de gestão da água. Para Pahl-Wostl (2009), a governança de água considera muitos processos dos quais a gestão da água faz parte. A definição de objetivos e estratégias para a tomada de decisão diz respeito à governança. As atividades de monitoramento dos recursos hídricos, assim como o desenvolvimento e a implementação de medidas que possam manter o estado dos recursos hídricos dentro do que se planejou, são atividades da gestão da água. A mesma autora (Pahl-Wostl, 2017) discute que a gestão hídrica pode ter desempenho inadequado em função de lacunas na sua implementação, lacunas nas habilidades apropriadas dos gestores da água e na ausência ou ineficiência de recursos financeiros.

Ménard et al. (2017), discutindo as lacunas na implementação das políticas hídricas, afirmam que parte do problema tem origem na não definição clara da natureza e das funções das instituições envolvidas na concepção, implementação e operacionalização das políticas. Os autores fazem uma diferença entre múltiplas escalas de governo (supranacional, nacional, regional, local) (OECD, 2011) e camadas institucionais nas quais atuam distintas modalidades da governança. Nas camadas institucionais estão a camada macroinstitucional (na qual as regras gerais são definidas) e a camada microinstitucional (na qual 
operam os envolvidos, denominados de jogadores pelos autores). Há uma camada intermediária que precisa ser considerada a fim de fazer a correta ligação entre as camadas macro e micro: a mesoinstitucional. Quando essa ligação não é adequada, ocorrem os problemas. Mesoinstituições são entendidas como um conjunto de entidades e mecanismos (procedimentos) por meio dos quais as regras gerais são traduzidas, adaptadas e tornadas operacionais, provendo diretrizes para seus gestores e usuários e oferecendo retornos aos tomadores de decisão.

No que se refere aos aspectos da escala e necessidade de interação e integração entre atores, deve ser mencionada a recente reflexão feita pela Organização para a Cooperação e Desenvolvimento Econômico (OCDE). A Organização estabeleceu doze princípios para a governança das águas, os quais foram distribuídos em três dimensões (OECD, 2015): i) eficácia; ii) eficiência e iii) confiança e comprometimento. Os seguintes princípios tratam dos temas da escala e da necessidade de integração:

Na dimensão da eficácia: atribuição clara de papéis e responsabilidades na formulação de políticas da água, na sua implementação, na gestão operacional e na sua regulamentação, e promoção da coordenação entre as várias autoridades responsáveis (Princípio 1) e; gerenciar a água na(s) escala(s) apropriada(s) na bacia de forma a refletir as condições locais, procurando a coordenação entre diferentes escalas (Princípio 2).

$\mathrm{Na}$ dimensão da eficiência: produzir, atualizar e compartilhar dados e informações consistentes sobre a água em tempo útil, comparáveis e relevantes para as políticas da água e com ela relacionados, e utilizá-los para orientar, avaliar e melhorar a política da água (Princípio 5); assegurar que regulamentos consistentes (arcabouços regulatórios sólidos) para a gestão da água sejam efetivamente implementados e o seu cum- primento garantido, tendo em vista o interesse público (Princípio 7) e; promover a adoção e implementação de práticas inovadoras de governança da água entre autoridades responsáveis, graus de governo e partes interessadas relevantes (Princípio 8).

Na dimensão da confiança e comprometimento: promover o envolvimento das partes interessadas a fim de que possam contribuir para a formulação e implementação das políticas de água (Princípio 10) e; encorajar arcabouços de governança da água que ajudem a gerenciar compromissos entre os usuários de água, entre áreas urbanas e rurais e entre gerações (Princípio 11).

As lacunas nos aspectos da coordenação adequada entre as escalas de planejamento e entre os envolvidos (se a camada mesoinstitucional de Ménard et al. 2017 não existir ou não funcionar bem) terão como consequência prejuízos à governança de água e aos seus aspectos operacionais (a gestão de água). O desafio está em alcançar os elementos já elencados pela OECD (2015): o compartilhamento de informações, a colaboração na elaboração de arcabouços consistentes, a promoção de práticas inovadoras entre graus de governo, o gerenciamento de compromissos entre os envolvidos.

\subsection{0 caso brasileiro}

No Brasil, a Política Nacional de Recursos Hídri$\cos$ (PNRH), Lei Federal $n^{\circ}$ 9.433/1997, definiu o Sistema Nacional de Gerenciamento de Recursos Hídricos (SINGREH), o qual é constituído por órgãos colegiados (conselhos e comitês) e por órgãos gestores de recursos hídricos. Para implementar a PNRH, cinco instrumentos de gestão foram concebidos: planos de recursos hídricos, enquadramento dos corpos d'água em classes segundo os usos preponderantes, outorga dos direitos de uso da água, cobrança pelo uso da 
água bruta e sistema de informações sobre recursos hídricos. A atribuição de árbitro dos conflitos nas bacias, em primeira instância, foi destinada aos comitês de bacia.

Para o caso brasileiro, uma bacia pode ser de rio de domínio da União quando esse rio atravessa mais de um estado (ou se constitui na própria divisa entre estados) ou poderá ser de domínio estadual (quando se insere totalmente em território estadual). Além do aspecto do domínio da água entre União e estados, a PNRH assume que a bacia hidrográfica é a unidade de planejamento, o que faz com que três escalas de planejamento se apresentem: a bacia, a União e os estados.

Discussões recentes, algumas das quais motivadas pela crise hídrica que o país vivenciou e ainda vivencia, seja no seu semiárido ou em outras regiões, apontam os avanços ainda necessários a serem alcançados na implementação da gestão hídrica brasileira (LIBÂNIO, 2018; NETO et al., 2018; RIBEIRO, 2017; BARBOSA et al., 2016; SOUSA JÚNIOR et al., 2016; SIEGMUND-SCHULTZE et al., 2015; VEIGA; MAGRINI, 2013). A integração entre as escalas de planejamento é um desses desafios. Apesar de concebido enquanto um sistema harmônico, o SINGREH tem tido dificuldades para realizar a integração entre entidades que atuam na escala da União, do Estado e das bacias e sub-bacias. Essa integração é essencial a fim de que os instrumentos de gestão definidos pela PNRH possam ter um grau de implementação análogo na bacia e em suas sub-bacias. Apenas com uma implementação ocorrendo de forma integrada entre diferentes escalas e no mesmo grau de qualidade, a governança da água na bacia como um todo (o que inclui, obrigatoriamente, as suas sub-bacias) poderá ser eficaz, eficiente e contar com a confiança e o comprometimento dos envolvidos. Elemento fundamental em tal processo são os planos de recursos hídricos. Há de se ter compatibilidade entre o plano nacional, os planos dos estados que fazem parte da bacia em foco, o plano da bacia e os planos das sub-bacias. Apenas assim será possível alcançar uma gestão que esteja atrelada às políticas nacionais, estaduais e que possa prioriza as condições locais.

Nesta pesquisa, desenvolve-se uma metodologia para verificar o grau de implementação da PNRH por meio de sete critérios: os cinco instrumentos de gestão da Lei $n^{\circ}$ 9.433/1997 e dois critérios relacionados à participação pública e gestão de conflitos, (i) existência e atuação dos comitês de bacia e incidência e, (ii) resolução dos conflitos pelo uso da água na bacia. Para aplicação deste modelo foram consideradas duas escalas de planejamento: macro (bacia de rio de domínio da União) e micro (bacia de rio de domínio estadual). Selecionou-se a bacia hidrográfica do rio São Francisco - BHSF (domínio da União) e uma de suas sub-bacias, a bacia do rio Salitre - BHS (domínio do Estado da Bahia) para análise.

\section{CASO DE ESTUDO}

A BHSF possui área de drenagem de $639.219 \mathrm{~km}^{2}$, o que corresponde a aproximadamente $8 \%$ do território brasileiro e $54 \%$ do semiárido, englobando sete unidades da federação (Minas Gerais, Goiás, Bahia, Alagoas, Sergipe Pernambuco e Distrito Federal) e 507 municípios. Há contrastes socioeconômicos e disparidades ambientais ao longo do percurso do rio principal (ASSIS; RIBEIRO; MORAES, 2018; CBHSF, 2016). A BHSF possui todos os instrumentos da PNRH implementados, há comitê de bacia e uma agência de bacia associada (Peixe Vivo). A área em estudo contempla uma série de conflitos pelo uso da água relacionados, principalmente, ao setor energético e ao uso para agricultura irrigada. A bacia é composta por 34 sub-bacias, dentre elas, destaca-se a sub-bacia do rio Salitre (BHS), na Bahia, com área de drenagem de 14.452 km² $^{2}(2,4 \%$ da área da BHSF) e que possui aproximadamente 14 tributários. A sub-bacia compreende uma re- 
gião com intensa atividade agrícola. Há conflitos reais e potenciais pelo uso da água na Bacia do rio São Francisco (CBHS, 2017; CBHSF, 2016; TORRES; MEDEIROS; FREITAS, 2016).

No caso do Estado da Bahia, no qual se localiza a sub-bacia do rio Salitre, a Política Estadual de Recursos Hídricos (Lei Estadual n 11.612/2009) define como instrumentos de gestão dos recursos hídricos: i. Plano Estadual de Recursos Hídricos (PERH); ii. Planos de bacias hidrográficas; iii. Enquadramento dos corpos d'água em classes, segundo os usos preponderantes; iv. Outorga de direito de uso dos recursos hídricos; v. Cobrança pelo uso da água; vi. Sistema Estadual de Informações Ambientais e de Recursos Hídricos (SEIA); vii. Qualidade e o monitoramento dos recursos hídricos; viii. Fiscalização do uso de recursos hídricos; iv. Fundo Estadual de Recursos Hídricos da Bahia (FERHBA). Nota-se que os instrumentos elencados possuem equivalência com os da PNRH, havendo alguns outros instrumentos contemplados no plano estadual. As bacias hidrográficas descritas, com suas respectivas localizações, estão na Fig. 1.

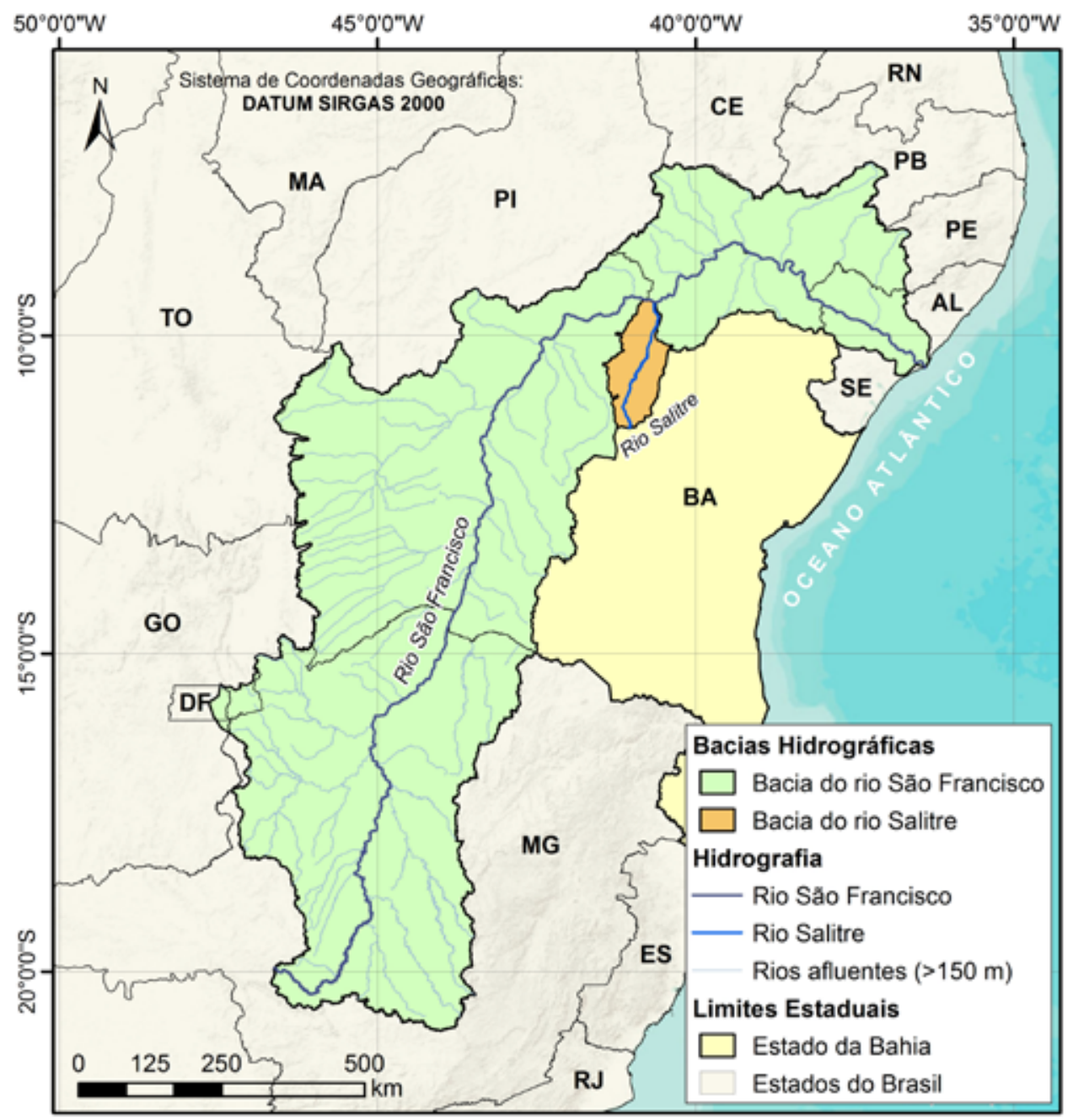

Figura 1 - Localização das bacias hidrográficas do rio São Francisco e rio Salitre, com sua hidrografia principal e limites políticos estaduais.

Fonte: Elaborada a partir de ANA (2017) e IBGE (2018). 


\section{METODOLOGIA}

Duas variáveis foram definidas e sete critérios foram escolhidos para analisar o grau de implementação da política hídrica na BHSF e na BHS, conforme apresentados na Tabela 1. Esses critérios são os cinco instrumentos de gestão dos recursos hídricos da Lei n 9.433/1997, e há dois critérios relacionados à participação pública e gestão de conflitos.

Para definição dos graus de avaliação dos critérios estabelecidos (Tabela 1) utilizou-se a pesquisa de Campos, Ribeiro e Vieira (2013), que construíram indicadores de sustentabilidade hídrica: IPDD (Indicador de Potencialidade, Disponibilidade e Demanda) e IGRH (Indicador de Desempenho do Sistema de Gestão de Recursos Hídricos). O IGRH é composto por três índices: Comitês de Bacia Hidrográfica (ICBH), onde é avaliada a existência e grau de atuação de comitê; Outorga (IO), no qual verifica-se o grau de implementação da outorga; Cobrança (IC), que, por sua vez, considera o grau de implantação da cobrança. A pesquisa estabeleceu as seguintes categorias de graus de desempenho: Muito Alto, Alto, Médio, Baixo e Muito Baixo.

Tabela 1 - Variáveis e critérios de avaliação.

\begin{tabular}{|c|c|}
\hline \multirow{2}{*}{ Variáveis } & $\begin{array}{c}\text { Critérios de avaliação } \\
\text { Outorga dos direitos de uso da água }\end{array}$ \\
\cline { 2 - 2 } $\begin{array}{c}\text { Instrumentos } \\
\text { de Gestão }\end{array}$ & $\begin{array}{c}\text { Cobrança pelo uso da água bruta } \\
\text { Plano de bacia hidrográfica }\end{array}$ \\
\cline { 2 - 2 } & $\begin{array}{c}\text { Enquadramento dos corpos d'água em } \\
\text { classes de usos }\end{array}$ \\
\cline { 2 - 2 } & $\begin{array}{c}\text { Sistema de informação sobre } \\
\text { recursos hídricos }\end{array}$ \\
\hline \multirow{2}{*}{$\begin{array}{c}\text { Participação pública e } \\
\text { gestão de conflitos }\end{array}$} & Existência e atuação do comitê de bacia \\
\cline { 2 - 2 } & $\begin{array}{c}\text { Incidência e resolução de conflitos pelo } \\
\text { uso da água }\end{array}$ \\
\hline
\end{tabular}

Algumas adaptações foram realizadas para ajustar a metodologia de Campos, Ribeiro e Vieira (2013) às necessidades desta pesquisa. Os graus foram utilizados como base para todos os sete critérios. Houve modificações nas descrições dos critérios para as variáveis outorga, cobrança e existência e atuação dos comitês de bacia para melhor se adequarem ao caso de estudo. A descrição para os graus das variáveis "Planos de bacia", "Enquadramento" e "Sistemas de informações", não consideradas em Campos, Ribeiro e Vieira (2013), foi realizada por este estudo.

Os graus e a respectiva descrição referentes ao critério "Existência e resolução de conflitos" foi estruturada mediante a tipologia do Programa de Consolidação do Pacto Nacional pela Gestão de Águas (PROGESTÃO). Esse programa é de incentivo financeiro e foi desenvolvido pela Agência Nacional de Águas (ANA, 2016; LIBÂNIO, 2017) em apoio aos Sistemas Estaduais de Gerenciamento de Recursos Hídricos (SEGREHs). $\mathrm{O}$ alcance das metas é definido a partir da complexidade da gestão em cada estado brasileiro. Cada unidade da federação encontra-se enquadrada em uma das quatro tipologias propostas (A, B, C e D) - (Tabela 2).

Cada critério analisado na metodologia proposta neste artigo apresenta cinco graus, portanto as tipologias do PROGESTÃO (definidas em quatro classes) foram adaptadas de forma a compreender esses cinco graus. As tipologias do PROGESTÃO (Tabela 2) tiveram a seguinte equivalência aos graus da variável "gestão de conflitos" (Tabela 3): Tipologia A - grau "Muito Baixo"; Tipologia B - grau "Médio"; Tipologia C - grau "Alto"; Tipologia D - grau "Muito Alto". Foi criado o grau "Baixo", o qual corresponde àquela situação de baixa incidência de conflitos, ou seja, os conflitos existem, porém não chegam a atingir todas as áreas consideradas como críticas.

Tabela 2 - Tipologias do PROGESTÃO (Classes de gestão).

\begin{tabular}{|c|c|}
\hline A & Bacia com usos pontuais e dispersos: Ausência de conflitos \\
\hline B & Presença de conflitos pelo uso da água em sub-bacias críticas \\
\hline$C$ & $\begin{array}{c}\text { Bacia com conflitos pelo uso da água com maior intensidade e } \\
\text { abrangência }\end{array}$ \\
\hline D & $\begin{array}{l}\text { Bacia com conflitos pelo uso da água generalizados e com } \\
\text { maior complexidade }\end{array}$ \\
\hline
\end{tabular}


Deste modo, a escala dos graus de classificação desta pesquisa é qualitativa e varia em intervalos que compreendem cinco graus - muito alto, alto, médio, baixo e muito baixo - que são aplicados aos sete critérios - outorga, cobrança, planos de recursos hídricos, enquadramento, sistemas de informação, comitês de bacia e conflitos pelo uso da água. Na Tabela 3 são apresentados os critérios, os graus e sua classificação, assim como a respectiva descrição.
A pesquisa bibliográfica, apoiando-se em documentos oficiais como os planos de recursos hídricos das duas bacias em análise, as informações dos órgãos gestores de recursos hídricos, a consulta às atas de reuniões dos respectivos comitês, permitiu proceder à categorização do grau de implementação da política hídrica face aos critérios estabelecidos. Os resultados e a discussão são apresentados no item que se segue.

Tabela 3 - Critérios, graus de classificação da implementação e respectiva descrição.

\begin{tabular}{|c|c|c|c|}
\hline \multicolumn{2}{|c|}{ Critério } & Grau & Descrição \\
\hline \multirow{25}{*}{ 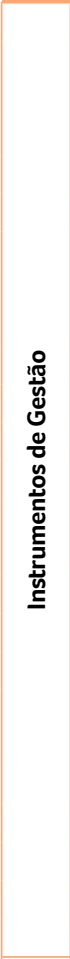 } & \multirow{5}{*}{ 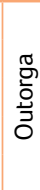 } & Muito alto & Outorga implantada com fiscalização total \\
\hline & & Alto & Outorga implantada com fiscalização parcial \\
\hline & & Médio & Outorga implantada com fiscalização inexistente \\
\hline & & Baixo & Outorga proposta em lei, em processo de implementação \\
\hline & & Muito baixo & Nenhuma ação no sentido de implantação da outorga na bacia \\
\hline & \multirow{5}{*}{ 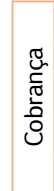 } & Muito alto & Cobrança estabilizada ${ }^{(1)}$, baixa taxa de inadimplência ${ }^{(2)}$ e alta eficiência do sistema de cobrança \\
\hline & & Alto & Cobrança em fase de adaptação ${ }^{(3)}$, média taxa de inadimplência e de eficiência do sistema de cobrança \\
\hline & & Médio & Cobrança implantada recentemente, déficit de arrecadação \\
\hline & & Baixo & Cobrança proposta em lei, em processo de implantação \\
\hline & & Muito baixo & Nenhuma ação no sentido de implantação da cobrança na bacia \\
\hline & \multirow{5}{*}{$\begin{array}{l} \\
\tilde{0} \\
\frac{\pi}{\alpha} \\
\frac{c}{\alpha}\end{array}$} & Muito alto & Plano com seu horizonte de planejamento atingido e com elaboração de atualizações \\
\hline & & Alto & Plano implementado e com boa parte de suas ações desenvolvidas \\
\hline & & Médio & Plano implementado recentemente \\
\hline & & Baixo & Proposta de elaboração do plano em andamento \\
\hline & & Muito baixo & Nenhuma ação no sentido de elaboração do plano na bacia \\
\hline & \multirow{5}{*}{ 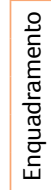 } & Muito alto & Proposta de enquadramento com seu horizonte de planejamento atingido, com elaboração de atualizações e ações desenvolvidas \\
\hline & & Alto & Proposta de enquadramento implementada, ainda no horizonte de planejamento e com boa parte de suas ações desenvolvidas \\
\hline & & Médio & Proposta de enquadramento elaborada recentemente \\
\hline & & Baixo & Proposta de enquadramento com elaboração em andamento \\
\hline & & Muito baixo & Nenhuma ação no sentido de elaboração da proposta de enquadramento \\
\hline & \multirow{5}{*}{$\bar{n}$} & Muito alto & Monitoramento e divulgação de informações atualizadas sobre os recursos \\
\hline & & Alto & Monitoramento e divulgação de informações, porém não atualizadas frequentemente \\
\hline & & Médio & O sistema existe, porém não é atualizado \\
\hline & & Baixo & Proposta de criação de um sistema de informações e em fase de implementação \\
\hline & & Muito baixo & Não há monitoramento sobre a situação quali-quantitativa dos recursos hídricos \\
\hline \multirow{10}{*}{ 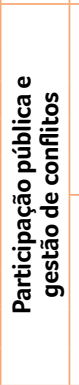 } & \multirow{5}{*}{ 恚 } & Muito alto & Comitê atuando há mais de 10 anos e alto índice de solução de problemas \\
\hline & & Alto & Comitê atuando há menos de 10 anos e médio índice de solução de problemas \\
\hline & & Médio & Comitê instalado recentemente e baixo índice de solução de problemas na bacia \\
\hline & & Baixo & Comitê proposto em lei, em processo de instalação \\
\hline & & Muito baixo & Nenhuma ação no sentido de criação de comitê de bacia \\
\hline & \multirow{5}{*}{ 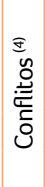 } & Muito alto & Conflitos generalizados e com maior complexidade, não restritos às áreas críticas \\
\hline & & Alto & Conflitos com maior intensidade de abrangência, mas ainda restritos às áreas críticas \\
\hline & & Médio & Conflitos pelo uso da água estão presentes somente em áreas críticas \\
\hline & & Baixo & Baixa incidência de conflitos \\
\hline & & Muito baixo & Ausência de conflitos \\
\hline
\end{tabular}




\section{RESULTADOS E DISCUSSÃO}

\subsection{Discussão sobre os sete critérios de avaliação}

\subsubsection{Instrumentos de Gestão}

\section{- Outorga dos direitos de uso da água}

Para a calha do rio São Francisco e para os demais corpos hídricos e reservatórios de domínio da União existentes, a autoridade outorgante e fiscalizadora é a ANA (Agência Nacional de Águas), que também tem a competência de emissão da reserva de disponibilidade hídrica para fins de aproveitamentos hidrelétricos. Embora a autoridade outorgante apresente um sistema eficiente de concessão de outorgas, há problemas relacionados às ações de fiscalização. Isso pode ser verificado no plano atualizado da BHSF (2016), onde, a partir da análise do cadastro de outorgas efetuadas na fase de diagnóstico, verificou-se uma divergência significativa entre vazões outorgadas e demandas.

As vazões outorgadas somam o valor de 723,4 $\mathrm{m}^{3} / \mathrm{s}$, enquanto a demanda total de recursos hídricos na bacia é estimada em 309,4 m³/s. Apesar dessa discrepância, existem ações de fiscalização na bacia do rio São Francisco feitas pela Superintendência de Fiscalização, por meio da Coordenação de Fiscalização de Uso. $O$ órgão emite relatórios anuais de suas atividades. O plano da BHSF informa que, ao analisar tais relatórios, verificou que houve fiscalização em alguns trechos da bacia de 2010 a 2014. A partir de 2015, embora a fiscalização exista, os relatórios não foram disponibilizados (CBHSF, 2016).

As outorgas no Estado da Bahia são emitidas na modalidade de autorização pelo INEMA (Instituto do Meio Ambiente e Recursos Hídricos), e sua implementação está prevista na Política Estadual de Recursos Hídricos. Compete aos Comitês de bacias da Bahia indicar ao CONERH-BA (Conse-
Iho Estadual de Recursos Hídricos da Bahia) os usos que dispensam outorga, as prioridades e critérios específicos de outorga em ocasiões de escassez, assim como critérios de racionamento e, ao aprovar o plano da bacia, definir estratégias para sua implementação. Ao Plano Estadual de Recursos Hídricos (PERH), por sua vez, cabe estabelecer prioridades e critérios mais gerais de outorga (CBHS, 2017). Para outorgas em rios intermitentes, cada caso é bastante específico, demandando assim um sistema de outorgas de recursos hídricos na base mensal ou concedidas apenas quando ocorrem vazões nos corpos d'água.

O INEMA tem a competência de fiscalizar preventivamente ou repressivamente, com poder de polícia administrativa, os usos dos recursos hídricos superficiais e subterrâneos baianos (SEIA, 2018). Durante a fase de diagnóstico para elaboração do plano da bacia do rio Salitre, detectou-se que um dos pontos fracos diante da gestão da bacia é a fiscalização insuficiente perante a emissão de outorgas. Este é um instrumento implantado na bacia do rio Salitre, porém com limitações de fiscalização (CBHS, 2017).

\section{- Cobrança pelo uso da água bruta}

O comitê da bacia hidrográfica do rio São Francisco (CBHSF) implementou a cobrança pelo uso da água em julho/2010, sendo o terceiro comitê a aplicar esse instrumento a recursos hídricos de domínio federal. São cobrados todos os usuários, com captação de água superior a 4,0 l/s com outorgas válidas. Cerca de $98 \%$ da cobrança incide sobre os usos quantitativos, e apenas $2 \%$ da cobrança realizada em toda a bacia incide sobre os usos qualitativos (CBHSF, 2016). Na Fig. 2 são demonstrados os valores cobrados e arrecadados com a cobrança na BHSF. 


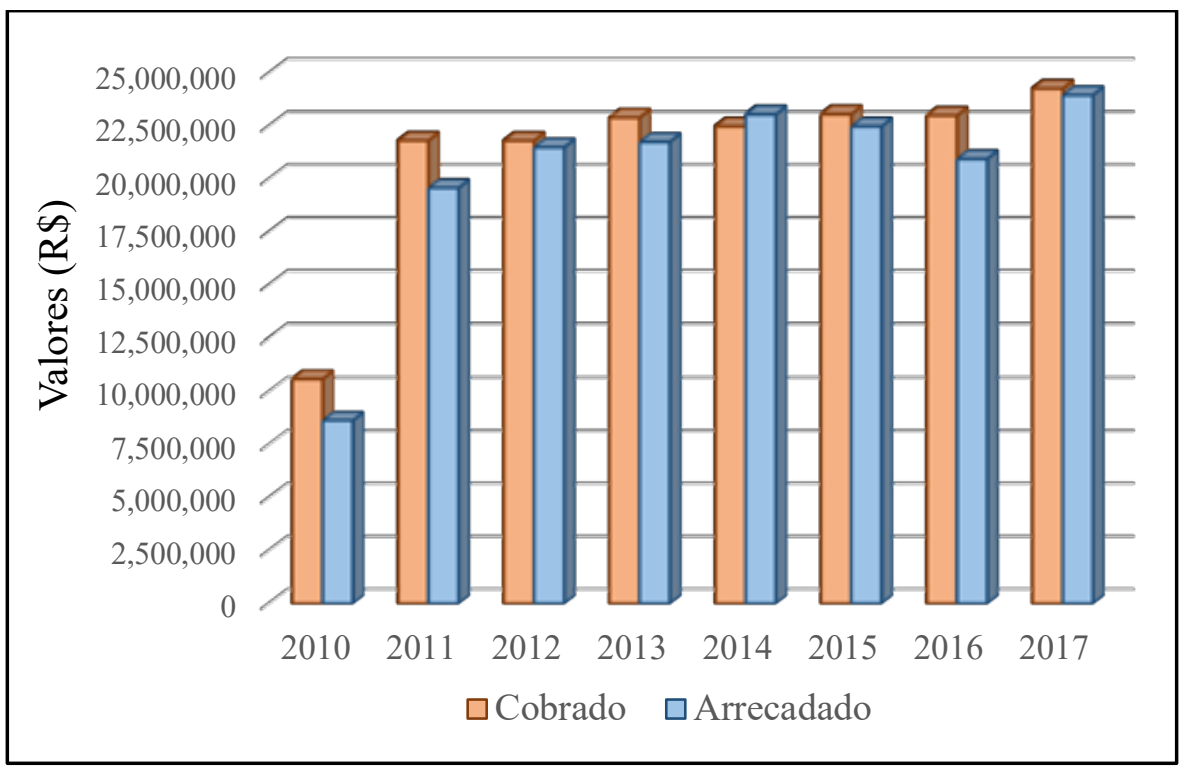

Figura 2 - Valores cobrados e arrecadados na BHSF. Fonte: ANA (2018).

De acordo com a ANA (2018), até janeiro de 2018, foram arrecadados $\mathrm{R} \$ 162.425 .151,32$. Desse valor, aproximadamente $65 \%$ compreendem os usuários do Submédio, com destaque para o Ministério da Integração Nacional, que desembolsa mais de R\$ 11 milhões anualmente pelas águas utilizadas e reservadas do Projeto de Integração do São Francisco. 0 índice de inadimplência anual é inferior a 5\%.

A metodologia de cobrança inicial adotada em 2010 foi atualizada em 2017, pela Resolução CBHSF n 94, de 25 de agosto de 2017. As alterações ocorreram nos três componentes da equação: base de cálculo, preços e coeficientes. A base de cálculo para usuários de lançamento de efluentes foi redefinida para uma equação que considera o volume de água que fica indisponível para uso após o lançamento; os preços foram atualizados, e os coeficientes, desenvolvidos para diferenciar melhor a cobrança para usuários distintos. Entretanto, a universalização da cobrança e a consideração de aspectos de variabilidade climática não foram adotadas, embora esse aspecto tenha sido discutido.

De acordo com o CBHS (2017), há um tipo de cobrança instituída no Estado da Bahia em 2005, pelo fornecimento de água bruta aos serviços de abastecimento público. Tem caráter de tarifa pelo serviço de captação da água dos reservatórios operados pelo Governo do Estado pela Empresa Baiana de Água e Saneamento (Embasa).

O Plano da Bacia Hidrográfica do rio Salitre (PBHS) sugere que seja adotado o modelo de cobrança existente na BHSF, a fim de que os usuários, independentemente de utilizarem as águas de domínio federal ou estadual, paguem de forma análoga. São realizadas simulações para estimar o potencial de arrecadação na BHS, com base nas demandas hídricas do ano de 2015, utilizando o antigo mecanismo de cobrança da BHSF. Obteve-se que o valor a ser gerado com a cobrança é da ordem de $\mathrm{R} \$ 73.756,00 / a n o$. De acordo com a Tabela 4, que descreve as estimativas de investimento nos programas da bacia do rio Salitre para todo o seu horizonte de planejamento (15 anos), observa-se que, tomando como base valores do ano de 2017, o valor anual arrecado com a cobrança na bacia (equivalente a uma média de $\mathrm{R} \$ 74.000 / a n o$ ) seria uma pequena parcela diante do total de investimentos calculados (PBHS, 2017). 
Tabela 4 - Estimativas de custo dos programas da Bacia Hidrográfica do rio Salitre

\begin{tabular}{|c|c|c|c|}
\hline Eixos & Programas & R\$ & $\%$ \\
\hline \multirow{4}{*}{ 1. Gestão e Governança das Águas } & 1.1. Programa de fortalecimento da Rede de Governança & 5.446 .197 & 3,3 \\
\hline & $\begin{array}{l}\text { 1.2. Programa de consolidação e implementação dos } \\
\text { instrumentos de gestão e planejamento dos recursos hídricos }\end{array}$ & 670.700 & 0,4 \\
\hline & 1.3. Programa de monitoramento dos recursos hídricos & 27.109 .000 & 16,4 \\
\hline & $\begin{array}{l}\text { 1.4. Programa de ampliação e consolidação da base de } \\
\text { conhecimentos sobre a BHS }\end{array}$ & 2.615 .000 & 1,6 \\
\hline 2. Saneamento e Qualidade da Água & $\begin{array}{l}\text { 2.1. Programa de ampliação e melhoria da infraestrutura de } \\
\text { saneamento básico }\end{array}$ & 44.107 .500 & 26,7 \\
\hline 3. Conservação ambiental & 3.1. Programa de proteção a área de produção hídrica & 4.454 .000 & 2,7 \\
\hline \multirow{2}{*}{$\begin{array}{l}\text { 4. Compatibilização das } \\
\text { disponibilidades e demandas }\end{array}$} & 4.1. Programa de ampliação da oferta de água & 68.914 .600 & 41,7 \\
\hline & 4.2. Programa de gestão da demanda & 12.047 .200 & 7,3 \\
\hline & Total & 165.384.197 & 100,0 \\
\hline
\end{tabular}

Fonte: CBHS, 2017.

\section{- Plano de bacia hidrográfica}

O primeiro plano decenal de recursos hídricos da bacia do rio São Francisco foi elaborado para a escala temporal de 2004-2013. Assim, com seu horizonte de planejamento atingido, uma nova versão foi preparada e, em meados de 2016, aprovada para atualizar, complementar e estabelecer novas metas e objetivos além dos já determinados e implementados pelo CBHSF no Plano Decenal (2004-2013). Os planos são decenais, e o que está em vigência possui seu horizonte de planejamento datando de 2016-2025, com ênfase, também, nas metas traçadas para intervalos de curto prazo ( 5 anos) e médio prazo (10 anos) (CBHSF, 2016).

O plano define objetivos, metas, orçamentos, financiamentos e entidades determinadas para executar toda a gestão e o planejamento necessários em todos os níveis espaciais, partindo do federal aos estaduais e locais, contando com o Comitê da BHSF e das bacias de rios afluentes. Os objetivos a serem alcançados são: a atualização dos diagnósticos; o fortalecimento do arranjo institucional; o aprimoramento dos instrumentos da PNRH, com ênfase à outorga e cobrança da água; determinação das ações prioritárias para a bacia; e, por fim, estruturação de uma base de dados referentes à bacia (CBHSF, 2016).
A bacia do rio Salitre apresenta o seu plano de recursos hídricos recém-elaborado, com sua versão final aprovada pelo comitê da bacia em outubro de 2017. Durante a sua elaboração foram definidos, a partir do diagnóstico realizado, quais os problemas com maior ênfase. Entre estes estão: insuficiência do monitoramento das águas superficiais; falta de fiscalização dos usos dos recursos hídricos; águas para abastecimento fora dos padrões de potabilidade (CBHS, 2017). Houve uma versão emergencial, que foi elaborada em 1993, porém seu horizonte de planejamento foi atingido desde 2003, o que o tornou longínquo para a análise de elaboração do plano em vigência.

O documento atual possui um horizonte de implementação de 15 anos (2017-2032), com metas em curto prazo (até 2021), que visam a fortalecer e aprimorar a governança das águas; médio prazo (até 2025), que pretende consolidar o instrumento de outorgas e o monitoramento da qualidade e quantidade dos recursos hídricos; e longo prazo (até 2032), que almeja implementar ações de saneamento, ações de melhoria de acesso às águas e implementação de programas de uso eficiente dos recursos em questão (CBHS, 2017). 


\section{- Enquadramento dos corpos d'água em classes}

Em consonância com a elaboração do PRHSF (Plano Decenal de Recursos Hídricos do rio São Francisco) 2004-2013, foi elaborada uma proposta de enquadramento dos recursos hídricos da bacia, porém essa ainda não foi aprovada pelo respectivo comitê. Com a atualização do plano (2016), esperava-se uma proposta de enquadramento concomitante, porém isso não ocorreu. Alegou-se que muitos dos corpos hídricos intermitentes existentes na bacia não possuem um monitoramento definido, de forma a impossibilitar a elaboração da proposta. O plano da bacia, entretanto, dispõe sobre algumas diretrizes de enquadramento para as águas da bacia (CBHSF, 2016). Em tal situação de ausência de proposta de enquadramento para a bacia, deve ser cumprida a legislação nacional vigente quanto aos padrões de qualidade das águas superficiais e subterrâneas.

A Fig. 3 apresenta as classes de qualidade das metas do enquadramento em vigência para os principais corpos d'água superficiais da bacia do rio São Francisco. Na sua maioria, os rios estão inseridos na Classe 2 da Resolução CONAMA 357 de 2005 ou não estão classificados.

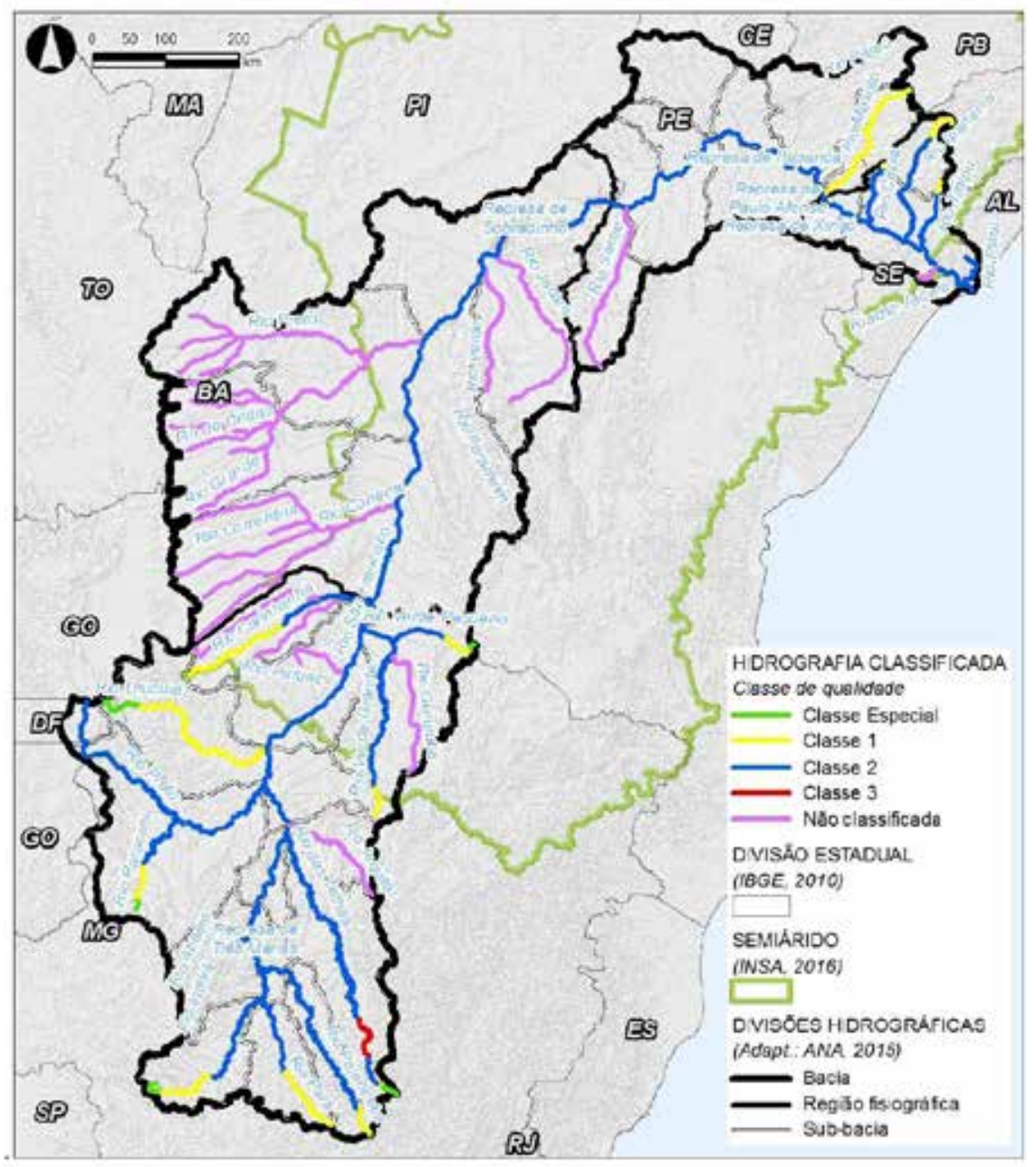

Figura 3 - Classe de qualidade do enquadramento vigente. Fonte: CBHSF, 2016. 
A proposta de Enquadramento dos corpos d'água da bacia hidrográfica do rio Salitre (Fig. 4) foi desenvolvida simultaneamente ao PRHS, tendo como base dados provenientes do Programa Monitora do INEMA, que é o órgão responsável por monitorar a qualidade das águas do estado da Bahia. O programa foi criado em 2008 com o intuito de aferir a qualidade das águas em seus múltiplos usos. Para a bacia do rio Salitre são monitorados quatro pontos. Desde o início do monitoramento foram realizadas 32 campanhas de coleta (duas destas em 2018), seguindo uma frequência de duas, três ou quatro campanhas ao ano (SEIA, 2018; CBHS, 2017).

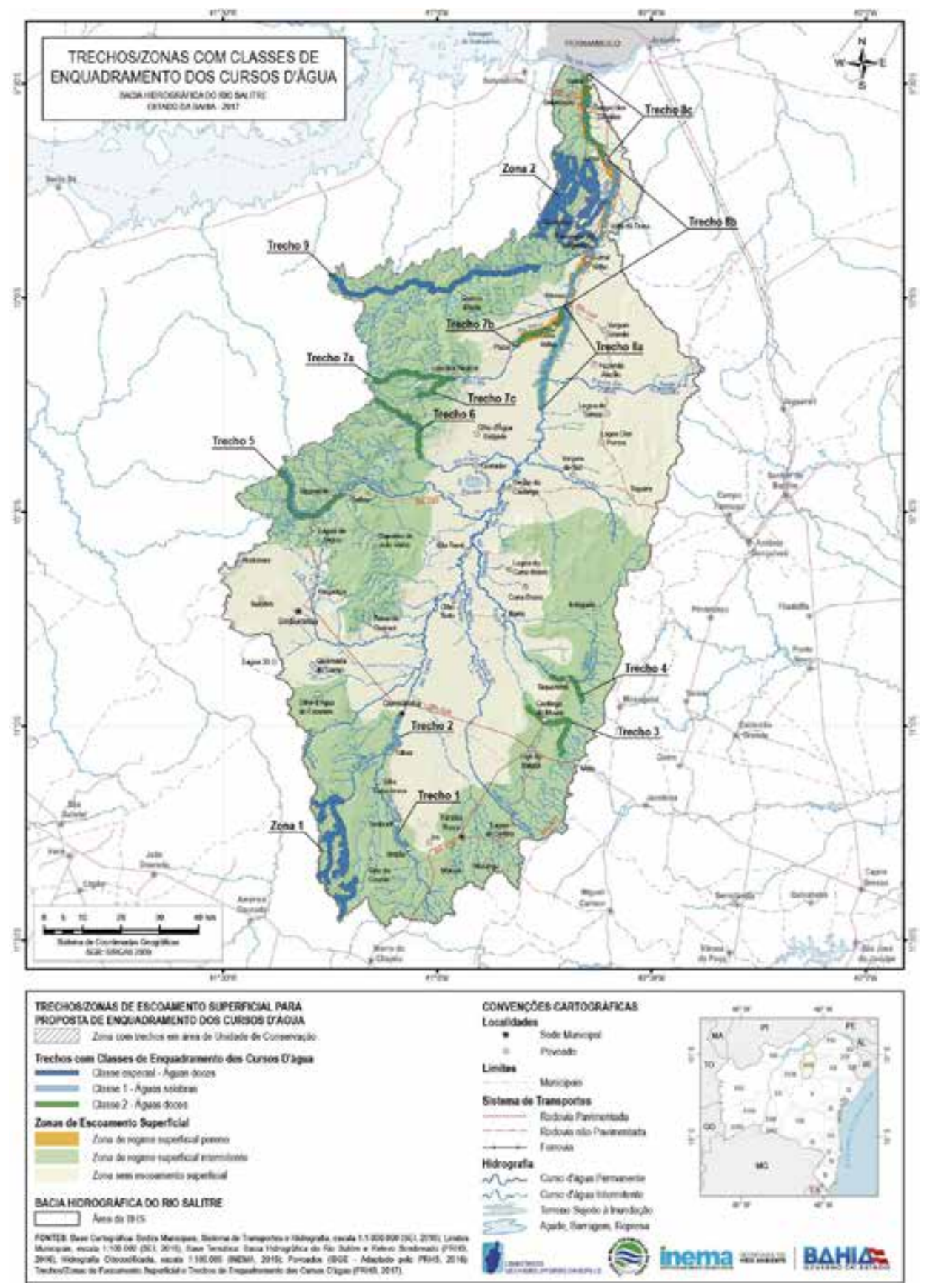

Figura 4 - Proposta de Enquadramento da BHS. Fonte: CBHS (2017). 


\section{- Sistema de Informação sobre Recursos Hídricos}

O Sistema Nacional de Informações sobre Recursos Hídricos (SNIRH) tem sua organização e gerenciamento feitos pela ANA. Há um Sistema de Informações Geográficas (SIG) atrelado ao SNIRH. O PRHSF contempla um Sistema de Informações sobre Recursos Hídricos (SIRH) contido no SNIRH, o qual apoiará os tomadores de decisão com o intuito de melhor gerir os recursos hídricos da bacia. A BHSF tem, portanto, como plataforma de sistema de informações, o SNIRH, por ser uma bacia com rio de domínio federal. Tal plataforma, atualizada frequentemente, funciona como referência aos sistemas estaduais (SNIRH, 2018; CBHSF, 2016).

O estado da Bahia possui o Sistema Estadual de Informações Ambientais e de Recursos Hídricos (SEIA), que visa a proporcionar à sociedade civil, aos usuários e ao poder público o acesso às informações e possibilitar uma melhor capacidade de tomada de decisões aos gestores. O Sistema possui um módulo de monitoramento que dispõe informações sobre o tempo, qualidade ambiental e recursos hídricos. A novidade disponível no portal é o SIGWeb do INEMA, intitulado GeoBahia, que se encontra em fase de aperfeiçoamento (SEIA, 2018; CBHS, 2017). Há preocupação do governo estadual com a disponibilidade de informações e, embora o sistema não esteja ainda em pleno funcionamento, o mesmo encontra-se em processo de atualizações.

\subsubsection{Participação Pública e Gestão de Conflitos}

- Existência e atuação do Comitê de Bacia

O Comitê da Bacia Hidrográfica do Rio São Francisco (CBHSF) é um órgão colegiado, criado em junho/2001 e que conta com 62 membros empenhados em realizar uma gestão dos recursos hídricos. É composto pelo poder público em seus três níveis - federal, estadual e local, usuários de água e sociedade civil com reuniões públicas duas vezes ao ano ou mais. Todas as atas das reuniões estão disponíveis no portal do CBHSF. Uma análise das atas mostra que o CBHSF atua já há 18 anos, sempre emitindo novas deliberações. O Comitê possui como entidade delegatária a agência de bacia AGB Peixe Vivo, que atua com o comitê da bacia desde 2010, arrecadando o montante proveniente da implantação da cobrança pelo uso da água e investindo nas ações propostas no PRHSF (CBFSF, 2018; CBHSF, 2016).

O comitê da bacia hidrográfica do rio Salitre foi criado em dezembro/2006 e é um órgão colegiado e participativo vinculado ao CONERH (Conselho Estadual de Recursos Hídricos), contando com 30 membros titulares que se reúnem duas vezes por ano ou mais. $O$ seu quórum é estabelecido com $2 / 3$ do total de membros, assim como na bacia do rio São Francisco. O CBHS participou efetivamente da formulação do PBHS. Em seu diagnóstico, um dos pontos fracos detectados foi uma "fraca participação do poder público municipal no Comitê de bacia". Um aspecto positivo foi a "atuação do comitê de bacia em todas as suas UPGRHs", além de já atuar há 12 anos. Suas atas de reuniões estão disponíveis no portal do INEMA, que exerce o papel de agência, já que este órgão inexiste na bacia. As UPGRHs (Unidades de Planejamento e Gestão dos Recursos Hídricos) consistem em uma divisão da bacia do rio Salitre em 7 recortes espaciais que objetivam facilitar a gestão na BHS (INEMA, 2018; CBHS, 2017).

\section{- Incidência e resolução de conflitos pelo uso da água}

A BHSF apresenta uma ampla extensão territorial e com isso uma alta complexidade de gerenciamento. A Bacia compreende sete entes da federação que devem se integrar em vários níveis espaciais para essa finalidade, o que torna inevitável a ocorrência de conflitos pelo uso da água. A região do Submédio é marcada por áreas críticas de incidência de conflitos, como é o caso da bacia do rio Salitre. Nas regiões do Alto, Submédio e Baixo São 
Francisco, evidenciam-se conflitos pelo uso da água entre o setor de geração de energia com os demais setores usuários (abastecimento humano, irrigação, turismo, entre outros). O CBHSF possui procedimentos de resolução de conflitos para algumas das suas áreas (CBHSF, 2016).

A bacia do rio Salitre, por sua vez, é uma área de grande relevância e complexidade de conflitos, que se agravam com a intermitência de seu rio principal. Isso se deve a uma escassa disponibilidade hídrica e à má distribuição de suas águas. As principais esferas de origem desses conflitos, de acordo com o PBHS (2017), são: i. uso da água para agricultura irrigada, principalmente no Perímetro Irrigado do Salitre (PIS), localizado na parte alta da bacia, comprometendo, assim, a oferta de água aos usuários do baixo Salitre; ii. a interrupção do curso do rio Salitre para a construção de barragens. A incidência de conflitos pode ser vista na Fig. 5, com destaque para os mais graves, que ocorrem na UPGRH 7 referente ao baixo Salitre (CBHS, 2017).

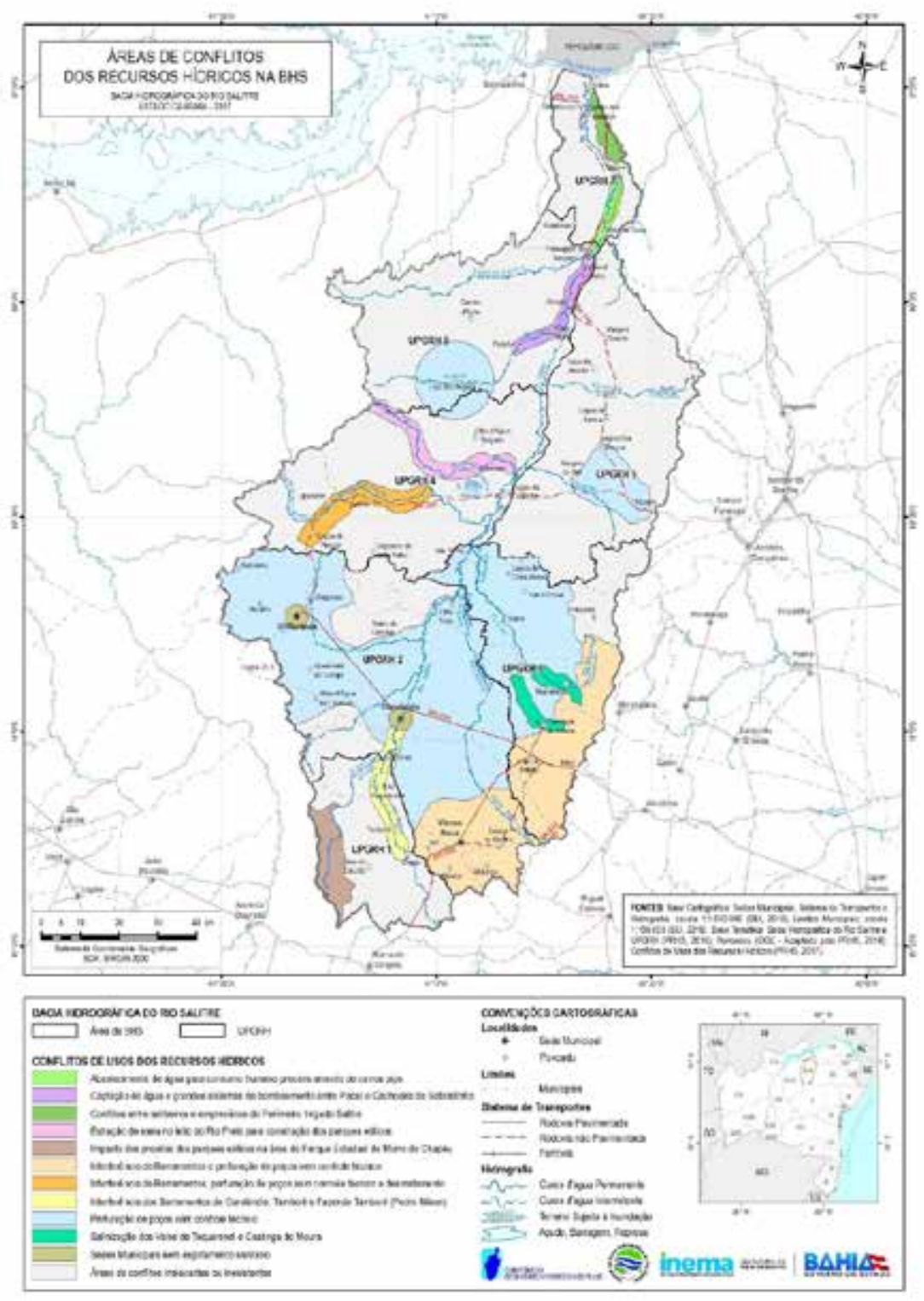

Figura 5 - Áreas de conflitos dos recursos hídricos na BHS. Fonte: CBHS (2017). 


\subsection{Classificação dos critérios em graus de implementação da PNRH}

De acordo com os graus de implementação definidos, os critérios selecionados para análise foram categorizados para as duas bacias em estudo. A análise permitiu identificar o grau de implementação da política hídrica e a comparação das situações entre as bacias dos rios São Francisco e Salitre. A Tabela 5 apresenta a classificação desses critérios para cada caso de estudo.

Tabela 5 - Categorização dos graus de implementação da política hídrica nas bacias hidrográficas.
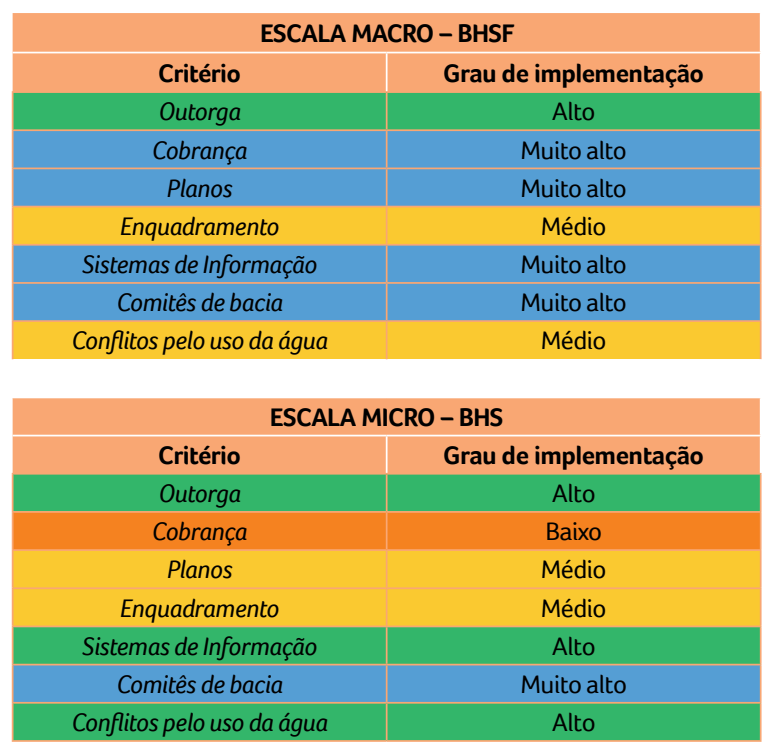

Fonte: Autoria própria.

Para a escala macro da pesquisa - bacia do rio São Francisco, o grau de implementação da PNRH foi classificado em "Alto" e "Muito Alto" para todos os critérios, com exceção do enquadramento e da incidência de conflitos pelo uso da água, que se enquadraram na categoria "Médio". A BHSF apresenta uma complexidade bem maior em sua gestão por ser uma bacia que apresenta um rio de domínio da União de importância nacional. Essa complexidade se deve por englobar entes de sete unidades da federação e 507 municípios, o que the confere acentuados contrastes socioe- conômicos. A bacia se apresenta com os instrumentos de gestão implementados e comitê de bacia atuante. Verifica-se que:

- Outorga: classificada na categoria de "Alto" grau de implementação, pois, para a bacia do São Francisco, o instrumento encontra-se já instalado, embora a fiscalização ocorra apenas parcialmente. Esse fato é verificado diante da divergência entre a vazão outorgada e a real demanda da bacia.

- Cobrança: a bacia apresenta uma cobrança estabilizada, iniciada em 2010 e atualizada em 2017, com previsão de ajuste de preços anuais, além de apresentar uma baixa taxa de inadimplência, apresentando, assim, um grau "Muito Alto" de implementação.

- Plano: classifica-se, de acordo com os graus propostos na metodologia, em "Muito Alto", pois o plano da bacia já teve o seu horizonte de planejamento atingido e sua atualização elaborada e divulgada em meados de 2016, com a realização das ações propostas.

- Enquadramento: se adequa ao grau "Médio", caracterizando que a proposta de enquadramento existe, embora não apresente informações para todos os corpos hídricos e consequentemente não ter aprovação do respectivo comitê de bacia.

- Sistema de Informação: a BHSF apresenta como plataforma de sistema de informações o SNIRH, que é atualizado frequentemente, funcionando como referência aos sistemas estaduais, classificando-se no grau "Muito Alto".

- Comitês: a atuação e articulação do comitê apresentou-se em grau de implementação "Muito Alto", com elevado índice de solução para os diversos problemas da bacia.

- Conflitos: quanto à ocorrência de conflitos pelo uso da água, a bacia apresentou-se com um grau 
"Médio" de acordo com a escala deste trabalho, tendo em vista que os conflitos estão presentes, embora nas áreas críticas.

Para a escala microbacia do rio Salitre, os graus obtidos variaram de "Baixo" até "Muito Alto". A análise verificou que:

- Outorga: a bacia apresenta um sistema de outorgas classificado como "Alto", indicando que o sistema de concessão de outorgas foi implantado, porém a fiscalização ocorre de forma parcial. Esse fato encontra-se diretamente atrelado a outro critério em análise, o instrumento de cobrança, pois, em bacias cuja cobrança pelo uso da água já se encontra implantada, a fiscalização de outorgas torna-se um pouco mais rigorosa, a fim de evitar desvios de água.

- Cobrança: devido à bacia não apresentar ainda a cobrança por água bruta implantada em seus recursos hídricos, o grau de implementação desse instrumento foi considerado "Baixo". A cobrança foi inserida no plano de recursos hídricos recém-aprovado da bacia do rio Salitre, porém ainda não foi posta em prática.

- Plano: a bacia do Salitre foi classificada em uma categoria de grau "Médio", no que se refere a esse instrumento. $\mathrm{O}$ documento foi elaborado em meados de 2017, e suas ações ainda estão em fase inicial de execução. Embora houvesse uma versão emergencial de Plano de Bacia, elaborado em 1993, seu horizonte de planejamento já estava desatualizado havia muito tempo.

- Enquadramento: o critério de enquadramento também se classificou como de grau "Médio" pelos mesmos motivos do plano da bacia. A proposta de enquadramento da bacia do rio Salitre foi elaborada concomitantemente ao plano da bacia.

- Sistema de Informação: o SEIA (Sistema Estadual de Informações Ambientais e Recursos Hí- dricos) é a plataforma de informações hídricas do estado da Bahia, e apresenta uma estrutura bem desenvolvida. Entretanto, a plataforma não é atualizada frequentemente, e para esse critério adotou-se a categoria de grau "Alto".

- Comitê: essa entidade atuou densamente nos últimos anos de 2016, 2017 e início de 2018, com um número relativo de reuniões e deliberações, buscando solucionar problemas primários de ordem urgente, como a elaboração do plano e da proposta de enquadramento. Portanto, classificou-se em um grau "Muito Alto" em função da sua existência há mais de 10 anos.

- Conflitos: a bacia do rio Salitre se caracteriza como uma área de grande relevância de conflitos, apesar da sua pequena extensão, possuindo uma maior intensidade destes no baixo Salitre. É uma área preocupante inserida na bacia do rio São Francisco, devido aos seus atritos entre os usuários do abastecimento público e os irrigantes. Esse critério tem classificação em grau "Alto": os conflitos pelo uso da água são de maior intensidade de abrangência, mas ainda assim restritos às áreas críticas.

\section{CONCLUSÕES}

Essa pesquisa propõe uma metodologia baseada em sete critérios (cinco instrumentos de gestão da Política Nacional de Recursos Hídricos e dois critérios relacionados à participação pública e resolução de conflitos) e cinco graus de classificação (Muito Alto, Alto, Médio, Muito Baixo e Baixo) a fim de identificar o estado de implementação da política hídrica. A observação de duas diferentes escalas de planejamento - escala macro (bacia do rio São Francisco) e escala micro (sub-bacia do rio Salitre-BA), permitiu verificar distintos graus de implementação da política hídrica em função da escala adotada. 
No que se refere aos instrumentos de gestão de recursos hídricos previstos na Lei nº 9.433/1997, pode-se concluir que todos já estão implementados na bacia hidrográfica do rio São Francisco. Essa é uma condição essencial para que sejam atingidos os objetivos da Política Nacional de Recursos Hídricos. A importância da integração desses instrumentos pode ser verificada nessa área de estudo. A implementação da cobrança, por exemplo, opera como um indicador da integração desses instrumentos, tendo em vista que a sua eficiência depende de outras informações contidas nas outorgas e nos dados cadastrados no CNARH (Cadastro Nacional de Usuários de Recursos Hídricos). Por dispor de plano de recursos hídricos atualizado, a bacia do rio São Francisco tem, por meio desse documento, as diretrizes para prosseguir na implementação da política hídrica pelos próximos anos e atingir as metas definidas com base em horizonte de planejamento preestabelecido.

Observa-se, entretanto, a pouca articulação e integração existente entre os órgãos estaduais e federais no que se refere à implantação dos instrumentos nos afluentes da bacia hidrográfica do rio São Francisco. É necessário que os instrumentos de gestão hídrica estejam implantados não apenas na calha do rio principal (São Francisco), mas em todas as sub-bacias, independentemente do domínio de suas águas, se do Estado ou da União. Essa ausência de simultaneidade na implantação da Política Nacional, por meio dos seus instrumentos, dá origem a uma série de conflitos pelo uso da água. Isso ocorre, pois, tomando como exemplo o instrumento da cobrança, quando esta é estabelecida apenas na calha do rio, alguns dos usuários migram para um rio afluente, que faz parte da própria bacia, que ainda não possui obrigatoriedade da cobrança, pois depende da aprovação em seu respectivo comitê de bacia. Isso passa a ter consequências na solicitação da outorga dos direitos de uso da água. O usuário, por não ser cobrado para usar a água bruta, poderá não considerar a outorga como uma prática essencial para a boa gestão das águas da bacia.

$\mathrm{Na}$ análise efetuada nesta pesquisa, fica evidente que os graus de implementação da política hídrica se apresentam com variações quando se comparam as situações na bacia de rio de domínio da União e na sub-bacia do rio Salitre. Apesar de ter área geográfica menor, a bacia estadual está sujeita, nesta sua pequena área, a mais conflitos pelos usos da água (grau "Alto” em comparação ao grau "Médio" da bacia do rio São Francisco). O critério "Conflitos" é, portanto, um indicador da implementação adequada (ou da ausência) dos instrumentos de gestão. Com Comitê de bacia em atuação mais destacada a partir de 2016, análises futuras dessa problemática poderão produzir resultados mais positivos para a subbacia do rio Salitre.

A pesquisa focou na escala de planejamento (denominada de "gerenciamento" por Daniell e Barretau, 2014) e suas vinculações com as escalas espacial (bacias hidrográficas); temporal (vazões a serem outorgadas, cobranças a serem praticadas, horizonte de planejamento dos planos de recursos hídricos); administrativa (nos níveis estadual e nacional); institucional (leis de recursos a serem seguidas, regras da outorga); de redes (interrelações entre entidades do sistema de gestão) e conhecimento e informação (essenciais para uso nas demais escalas).

Os resultados encontrados mostram que para garantir uma boa governança de água, a coordenação entre diferentes escalas é essencial. Para o caso estudado, as falhas mostradas por meio da avalição do grau de implementação da política hídrica enfatizam a importância do fortalecimento do sistema estadual de gestão de recursos hídricos, tornando-o mais compatível com os avanços já alcançados no domínio administrativo da União. 


\section{AGRADECIMENTOS}

A primeira autora agradece a bolsa de estudos concedida pelo Conselho Nacional de Desenvolvimento Científico e Tecnológico (CNPq), no período do Mestrado, no Programa de Pós-Graduação em Engenharia Civil e Ambiental da Universidade Federal de Campina Grande (UFCG). A quinta autora agradece à Fundação de Apoio à Pesquisa da Paraíba (FAPESQPB) e à Coordenação de Aperfeiçoamento de Pessoal de Nível Superior (CAPES), no âmbito do mesmo programa de pós-graduação.

\section{CONTRIBUIÇÃO DOS AUTORES}

Conceitualização, Brito YMAB, Ribeiro MMR, Silva SR, Medeiros YDP, Assis WD; Metodologia, Brito YMAB, Ribeiro MMR; Redação - Primeira versão, Brito YMAB, Ribeiro MMR; Redação - Revisão \& Edição, Brito YMAB, Ribeiro MMR, Silva SR, Medeiros YDP, Assis WD; Aquisição de Financiamento, Ribeiro MMR; Recursos, Ribeiro MMR; Supervisão, Ribeiro MMR, Silva SR

\section{REFERÊNCIAS}

ANA - Agência Nacional da Águas. PROGESTÃo - Programa de Consolidação do Pacto Nacional pela Gestão das Águas: Manual Operativo. Agência Nacional das Águas, 2016.

. ANA Metadados. Base Hidrográfica Ottocodificada da Bacia do Rio São Francisco. 2017.

Demonstrativo dos valores arrecadados por usuários: Bacia do rio São Francisco - exercícios 2010 a 2017. 2018.

ASSIS, W. D.; RIBEIRO, M. M. R.; MORAES, M. M. G. A Proposição de melhorias para o sistema de cobrança da bacia hidrográfica do rio São Francisco. Eng. Sanit. Ambient. v. 23, n. 4, p. 779-790, 2018.

AKHMOUCH, A.; CLAVREUL, D.; GLAS, P. Introducing the OECD Principles on Water Governance. Water International. v. 43, n. 01 , p. 5-12, 2017.

BAHIA (Estado). Lei n 11.612 de 08 de outubro de 2009. Dispõe sobre a Política Estadual de Recursos Hídricos, o Sistema Estadual de Gerenciamento de Recursos Hídricos, e dá outras providências. Salvador: Gabinete do Governo, 2009. Disponível em: <http://cbhsao francisco.org.br/wp-content/uploads/2012/05/
LEI-N\%C2\%BA-11.612-DE-08-DE-OUTUBRO-DE-2009.pdf>. Acesso em: maio 2018.

BARBOSA, M. C.; MUSHTAQ, S.; ALAM, K. Rationalising water policy and the institutional and water governance arrangements in Sao Paulo, Brazil. Water Policy, 18 (6), 1353-1366, 2016.

BRASIL. Lei Federal $n^{\circ}$. 9.433, de 08 de janeiro de 1997. Instituiu a Política Nacional de Recursos Hídricos e cria o Sistema Nacional de Gerenciamento de Recursos hídricos. Brasília - DF: D.O.U. de 09/01/1997. 1997. Disponível em: <http://www.planalto.gov. br/ ccivil_03/LEIS/L9433.htm>. Acesso em: maio 2018.

CAMPOS, M. V. C. V.; RIBEIRO, M. M. R.; VIEIRA, Z. M. C. L. A gestão de recursos hídricos subsidiada pelo uso de indicadores de sustentabilidade. Revista Brasileira de Recursos Hídricos, v. 19, n. 2, p. 209-222, 2013.

CBHS - Comitê da Bacia Hidrográfica do Rio Salitre. Plano de Recursos Hídricos e Proposta de Enquadramento dos Corpos de Água da Bacia Hidrográfica do Rio Salitre. Salvador: Comitê da Bacia Hidrográfica do Rio Salitre, 2017.

CBHSF - Comitê da Bacia Hidrográfica do rio São Francisco. Plano Decenal de Recursos Hídricos da Bacia Hidrográfica do Rio São Francisco - PBHSF (2016 2025): Resumo executivo. Alagoas: Comitê da Bacia hidrográfica do rio São Francisco, 2016.

Deliberação CBHSF nº 94, de 25 de agosto de 2017. Atualiza, estabelece mecanismos e sugere novos valores de cobrança pelo uso de recursos hídricos na bacia hidrográfica do rio São Francisco. Brasília - DF: CBHSF, 2017. Disponível em: < http:// cbhsaofrancisco.org.br/2017//box/uploads/2017/06/DELIBERACAO-CBHSF-No-94-2017-METODOLOGIA-DE-COBRANCCCA7A-E-PPU-PARA-A-BHSF.pdf>. Acesso em: maio 2018.

Comitê da Bacia hidrográfica do rio São Francisco. 0 CBSHF. 2018. Disponível em: <http://cbhsaofrancisco.org.br/>. Acesso em: 17 de out. de 2018.

DANIELL, K. A.; BARRETEAU, O. Water governance across competing scales: Coupling land and water management. Editorial. Journal of Hydrology, v. 519, p. 2367-2380.

IBGE - Instituto Brasileiro de Geografia e Estatística. Downloads Geociências. Organização do território > Malhas territoriais > Malhas municipais $>2018$.

INEMA - Instituto do Meio Ambiente e Recursos Hídricos. SEIA: Sistema Estadual de Informações Ambientais e de Recursos Hídricos. Módulo de monitoramento. 2018. Disponível em: <http:// monitoramento.seia.ba.gov.br/>. Acesso em: 17 de out. de 2018 .

LIBANIO, P. A. C. Promoting and assessing water governance at subnational level: the experience of Brazil's National Water Management Pact. Water International. v. 42, n. 4, p. 385-399, 2017.

LIBANIO, P. A. C. Two decades of Brazil's participatory model for water resources management: from enthusiasm to frustration. Water International, v. 43, n. 4, p. 494-511, 2018. 
MÉNARD, C.; JIMENEZ, A; TROPP, H. Addressing the policy-implementation gaps in water services: the key role of meso-institutions. Water International. v. 43, n. 1, p. 13-33, 2017.

NETO, S; CAMKIN, J; FENEMOR, A; TAN, PL; BAPTISTA, JM; RIBEIRO, M; SHULZE, R; STUART-HILL, S, SPRAY, C; RAHMAH, E OECD Principles on water governance in practice: an assessment of existing frameworks in Europe, Asia-Pacific, Africa and South America. Water International, v. 43, n. 1, p. 60-89, 2018.

OECD - Organization for Economic Cooperation and Development. Water Governance in OECD Countries: A Multi-level Approach. Paris: OECD, 2011.

OECD Principles on Water Governance. Paris: OECD, 2015.

PAHL-WOSTL, C. A. conceptual framework for analyzing adaptive capacity and multi-level learning processes in resource governance regimes. Global Environmental Change. v. 19, p. 354-365, 2009.

PAHL-WOSTL, C. An evolutionary perspective on water governance: From understanding to transformation. Water Resources Management, v. 31, p. 2917-2932, 2017.
RIBEIRO, M. M. R. A Few Comments on the Brazilian Water Resource Policy. New Water Policy \& Practice Journal, v. 3, n. 1 e 2, p. 22-32, 2017

SOUSA JÚNIOR, W.; BALDWIN, C.; CAMKIN, J.; FIDELMAN, P.; SILVA, O.; NETO, S.; SMITH, T. F. Water: Drought, crisis and governance in Australia and Brazil. Water, v. 8, n. 11, p. 493, 2016.

SIEGMUND-SCHULTZE, M.; RODORFF, V.; KOPPEL, J.; SOBRAL, M. C. Paternalism or participatory governance? Efforts and obstacles in implementing the Brazilian water policy in a large watershed. Land Use Policy, v. 48, p. 120-130, 2015.

TORRES, C. J. V.; MEDEIROS, Y. D. P. M.; FREITAS, I. M. D. P. Training watershed committee members to aid on the decision-making process for the execution program of the framework of water bodies. Revista Brasileira de Recursos Hídricos, v. 21, n. 2, p. 314327, 2016.

VEIGA, L. B. E.; MAGRINI, A. The Brazilian water resources management policy: Fifteen years of success and challenges. Water Resources Management, v. 27, n. 7, p. 2287-2302, 2013. 